\title{
Modelling Syntectonic Sedimentation: Combining a Discrete Element Model of Tectonic Deformation and a Process-based Sedimentary Model in 3D
}

\author{
A. Carmona • R. Clavera-Gispert • O. Gratacós • \\ S. Hardy
}

Received: 17 November 2009 / Accepted: 28 May 2010 / Published online: 11 June 2010

(C) International Association for Mathematical Geosciences 2010

\begin{abstract}
This paper presents a new numerical program able to model syntectonic sedimentation. The new model combines a discrete element model of the tectonic deformation of a sedimentary cover and a process-based model of sedimentation in a single framework. The integration of these two methods allows us to include the simulation of both sedimentation and deformation processes in a single and more effective model. The paper describes briefly the antecedents of the program, SimsafadimClastic and a discrete element model, in order to introduce the methodology used to merge both programs to create the new code. To illustrate the operation and application of the program, analysis of the evolution of syntectonic geometries in an extensional environment and also associated with thrust fault propagation is undertaken. Using the new code, much more complex and realistic depositional structures can be simulated together with a more complex analysis of the evolution of the deformation within the sedimentary cover, which is seen to be affected by the presence of the new syntectonic sediments.
\end{abstract}

Keywords Process based sedimentary models - Discrete element technique · Syntectonic sedimentation

\footnotetext{
A. Carmona $(\bowtie) \cdot$ O. Gratacós · S. Hardy

GEOMODELS Research Institute, and GGAC Grup de Geodinàmica i Anàlisis de Conques, Facultat de Geologia, Universitat de Barcelona, c/Martí i Franquès s/n, 08028 Barcelona, Catalonia, Spain e-mail: anacarmona@ub.edu

R. Clavera-Gispert

Abteilung Geologie, Facultat für Biologie, cheime und Geowissenschaften, Universität Bayreuth, Bayreuth, Germany

S. Hardy

Icrea (Institució Catalana de Recerca i Estudis Avançats), Barcelona, Catalonia, Spain
} 


\section{Introduction}

As a result of improvements in computer technology since the 1970s, numerical modelling has become an essential tool in the analysis of geological processes. $\mathrm{Nu}-$ merical modelling may assist the understanding of geometries, architectures, and processes difficult to otherwise observe in nature or to understand by simple conceptual models. Moreover, it has also become a useful validation tool for other methods such as 3D reconstruction or analogue modelling. There are many published numerical models of sedimentation in basins (e.g. Tetzlaff and Harbaugh 1989; $\mathrm{Li}$ and Amos 2001). These have treated the simulation of sedimentation from different points of view and using different techniques (e.g. Grajeon and Joseph 1999; Hardy and Gawthorpe 1998), and they can provide physical, chemical, and petrologic information about different sedimentary bodies. These numerical tools also allow the prediction of the spatial and temporal distribution of these sedimentary bodies and their internal architectures. Similarly, there is a wide range of tools, including kinematic (e.g. Hardy and McClay 1999) and mechanical models (e.g. Allmendinger 1998; Johnson and Johnson 2002; Simpson 2006; Strayer and Suppe 2002), able to simulate deformation at scales from a thin sedimentary cover to full orogenic geometries. A variety of numerical techniques have been used to implement these models, ranging from finite elements (e.g. Cardozo et al. 2003) to discrete elements (e.g. Finch et al. 2003, 2004).

Considering the importance of deformation processes on final geometry, as well as fracture and deformation patterns of sedimentary bodies, it is necessary to consider deformation and sedimentary processes at the same time. If this approach is adopted, a more realistic geological model may be obtained. Both processes working together imply more than each working separately because one process is affected by the other and vice versa (i.e. there is feedback and interaction). From the point of view of the deformation, the addition of new sediments to a deforming section affects its evolution. On the other hand, deformation affects previously deposited sediments and basin geometries, thus creating a depositional environment that is going to directly affect the deposition of new sediments. Some numerical modelling approaches are able to reproduce both sedimentation and deformation at the same time, treating their interaction in 2D and also 3D. Some are focussed on how the deformation rate is affected by sedimentation and erosion (e.g. Maniatis et al. 2009), while others just include sedimentation as an additional phenomenon in the study of crustal rocks subject to specific tectonic boundary conditions (e.g. Gawthorpe and Hardy 2002; Simpson 2009). However, in these papers, transport and sedimentation processes are modelled either by a simple diffusive equation or treated simply as a refill process, but not as a real process that follows physical rules of transport and sedimentation.

To combine realistic models of deformation and sedimentation is the main aim of the new numerical computer program presented here. A new code has been developed to combine mechanical and sedimentary process-based numerical models. Combining these two approaches allows us to include the simulation of both sedimentation and deformation processes in a single and more realistic model. This new tool results from the merging of two previous published works: Simsafadim-Clastic (Bitzer and Salas 2002; Gratacós 2004; Gratacós et al. 2009a) and a discrete element 
model or DEM (Finch et al. 2003, 2004; Hardy and Finch 2005, 2006, 2007; Hardy et al. 2009). The former simulates sub-aquatic clastic transport and sedimentation in three dimensions, including processes of interaction, production, and sedimentation of carbonates; moreover, it is also a powerful tool for the $3 \mathrm{D}$ prediction of stratigraphic structures and facies distribution modelling in sedimentary basins. The latter deals with the simulation of the deformation in sedimentary rocks in $2 \mathrm{D}$ and 3D. This deformation is a consequence of interaction of many individual elements according to mechanical rules. The main goal of merging these two methods is to develop a new tool that will be able to offer a more complex and realistic study of the evolution of the structures and deformation in sedimentary materials produced by faults and folds. Deformation is based on mechanical rules and is therefore influenced by the presence of syntectonic sediments. In addition, the tectonic processes change the topographic surface, which influences fluid flow, transport, and, consequently, sedimentation in the process-based sedimentary model. Finally, analysis of the evolution of deformation within these new syntectonic materials can also be performed. The understanding of the development and characteristics of these syntectonic architectures is important in many areas of structural geology, such as hydrocarbon prospecting and evaluating the stratigraphic architectures in sedimentary basins, among others.

\section{Combining Process-based Sedimentary Models and Discrete Element Modelling}

\subsection{Background}

For a better and easier understanding of how the new code works, it is essential to give a short overview of the procedure and methodology of its component parts. We now summarize how Simsafadim-Clastic and the discrete element model work. For more detailed information on both codes, the reader is referred to more detailed descriptions in Gratacós (2004), Gratacós et al. (2009a, 2009b) for the Simsafadim-Clastic program; see Finch et al. (2004) and Hardy and Finch (2005) for the DEM program.

\subsubsection{Simsafadim-Clastic}

Simsafadim-Clastic program is a 3D process-based numerical forward model, which simulates clastic transport and sedimentation including carbonate production, transport, and sedimentation. Initial basin topography is discretized using triangular finite elements. These elements will be the basis to develop and solve the differential equation that manages the fluid flow and transport processes. The nodes of these triangles are also used to solve the remaining equations that describe sedimentation and carbonate production. Total simulation time is discretized according to the Courant criterion, which gives interval time steps to ensure the stability of the differential equation solutions (Gratacós 2004). The fluid flow system is a 2D potential model (Bitzer and Salas 2002) in a transitional pattern. It assumes a laminar, non-viscid, and irrotational fluid, without short-time processes. The fluid flow value in each node depends on the water depth, but it is considered constant along the water column. The equation is 
solved using the finite element method (Kinzelbach 1986). The transport model assumes that the sediment is transported in suspension mainly by advection processes as a result of the fluid flow velocity. It also considers dispersion and diffusion terms as a result of shorter transport processes such as organic activity or wave action. The sediment is uniformly distributed in the water column in order to simulate a turbulent transport process. The transport equation is also solved by the finite element method for each clastic sediment type (Kinzelbach 1986). The sedimentation model assumes that a particle is susceptible to settling when the fluid flow linear velocity is lower than a critical settling velocity. This critical settling velocity is defined for each sediment type according to its density and its grain size. The final settling velocity of a particle is modified according to a linear dependence between the flow linear velocity and its theoretical critical settling velocity. Despite the fact that Simsafadim-Clastic can efficiently model the distribution of facies and the depositional architectures in a sedimentary basin, the program has some limitations that can affect the final result. The main limitation is the static basement consideration as no tectonic movements are considered, although the program considers isostacy as well as subsidence due to the weight of the new materials.

\subsubsection{Discrete Element Modelling (DEM)}

The discrete element technique is used to model and investigate, in $2 \mathrm{D}$ and $3 \mathrm{D}$, the propagation and evolution of deformations in sedimentary cover caused by tectonic movements that affects the rigid boundary of the model, e.g. detachment folding (Hardy and Finch 2006), thrust/extensional fault-propagation folds (Finch et al. 2003, 2004; Hardy and Finch 2005), doubly vergent thrust wedges (Hardy et al. 2009) and evolution of calderas (Hardy 2008). The model approach is a variant of the "Lattice Solid Model" (Mora and Place 1993, 1994). A detailed description of the LSM is given by the cited articles. An outline of the model approach and its implementation is given here (for a full description, also see Finch et al. 2004; Hardy and Finch 2005). An assemblage of spherical elements of different radii is used to model the rock mass; this allows a random position of the elements avoid any isotropy or any likelihood for preferred planes of weakness (Hardy and Finch 2006). The evolution of the system is realized through the interaction and behaviour of these elements. These discrete elements interact in pairs through a repulsive-attractive force as if they are connected by breakable elastic springs. A breaking separation is defined, a particle is bonded until the separation between them exceeds this lower limit, and after that the bond is irreparably broken. Nevertheless, the repulsive force can act again between them if the particle pair goes back to a compressive contact. To calculate the total elastic force applied on a particle is only necessary to do the sum of the forces on each bond that link the particle to its neighbours. The body is elastic-plastic and can consider friction. But the precise mechanics of the assemblage are not discussed here. The importance is the transfer of the resultant deformation to the sedimentary model. The gravitational force, acting in each element, is also added. In addition, a viscous damping term is included. This viscous term is proportional to the particle velocity and it is considered in order to make the model less dynamic and more quasi-static, which is more suitable for modelling the development of tectonic structures over long time scales. This assemblage is confined into a bounding box. The 
base of the box is supposed to be the basement and is considered to be rigid and undeformable, only affected by the small displacements with which the deformation is simulated. These displacements are performed to the bounding box in each time step according to the boundary conditions chosen: a normal fault, strike-slip, a detachment fold, etc. The time step is chosen to ensure numerical precision and stability (Mora and Place 1994). At each discrete time step, particles proceed to their new position by integrating their equation of motion using Newtonian physics and velocity Verlat Scheme (Allen and Tidsley 1987). Some 2D configurations of this model allow us to add syntectonic materials during the evolution of the model, but this is just a refill of the created accommodation space, not a real process of sedimentation. Not considering sedimentation process during the evolution of the model is the current main limitation of the discrete element model.

\subsection{Merging}

Taking into account the limitations of Simsafadim-Clastic and DEM, merging provides us a new tool for geological modelling that addresses the main limitations of both programs, complementing each other. The new tool can predict and analyse other different syntectonic depositional architectures with more complex geological scenarios. It also allows a more realistic study of the evolution of deformation produced by faults and folds since the contribution of new sediments to the system is considered. Sediments come from a source and they undergo transport and settle, which are also a function of the new relief that is constructed. An appropriate approach to combing both codes would be to create a link between the two models that allows us to run them separately without mixing up the two methods. This link is created using the spheres located on the assemblage surface that define the initial topography of the basin used by the Simsafadim-Clastic program. The idea is that this initial basin topography, discretized into a triangular finite element mesh, will adapt to the movement of the spheres on the DEM surface. To do this, the mesh is established over this assemblage surface. The $z$ position of each node is given by the average position of the four spheres of the assemblage surface located closest to the $x-y$ node position (Fig. 1). To choose the time step, we checked the requirements of the discretization time for convergence and stability of the mathematical methods used in each program (Gratacós 2004; Hardy and Finch 2006). The smallest $\Delta t$ is selected in order to ensure proper results for both programs. The two programs are thus run separately but concurrently, and for each time step $\Delta t$ the interaction between them is calculated and the $z$ values of the nodes are updated. This value is determined by the new position of the balls that make up the surface at the current time step, plus the sediment that SimsafadimClastic had added to each node (which is taken into account by the SimsafadimClastic code). This implies that the changes in the topography of the basin are now controlled by two factors: tectonic movements and sedimentation. When the amount of sediment deposited in the model is higher than a critical value (this means having a number of nodes with an amount of sediment equal to or bigger than the diameter of a sphere), a transfer from Simsafadim-Clastic to the discrete element model takes place. In this transfer, the space taken up by the new sediment is refilled with new discrete 


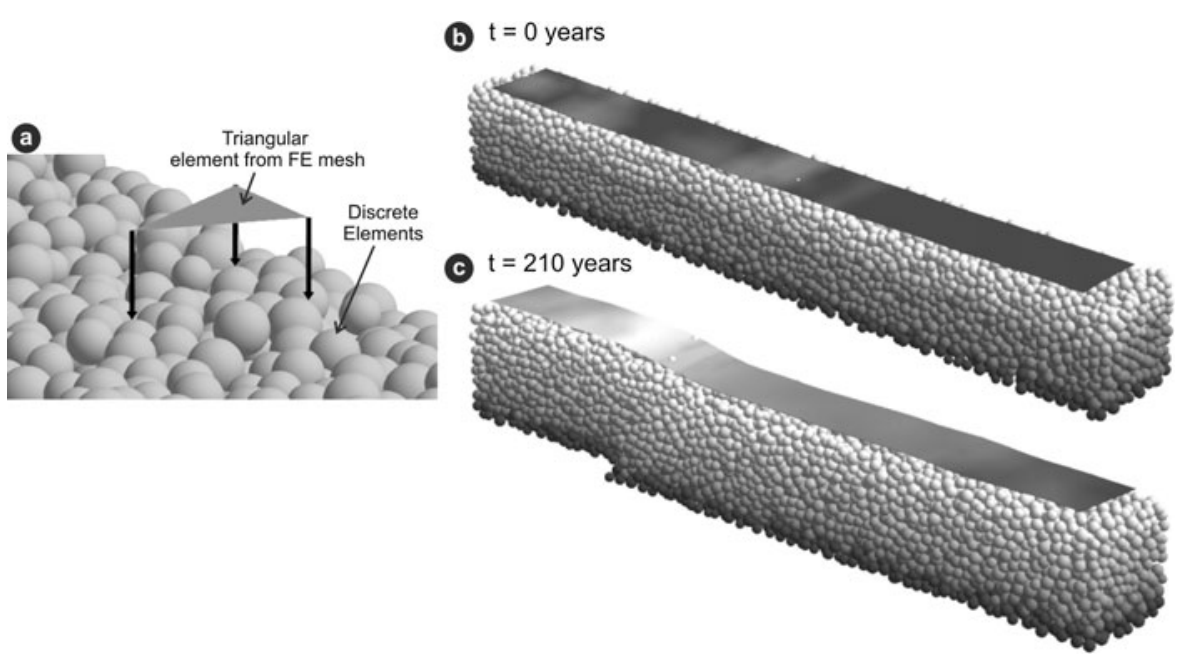

Fig. 1 (a) Finite element mesh allocation over the surface of the sphere assemblage. Each node of the element looks for the four spheres of the surface that are closest to its $x-y$ position and it takes average $z$ value of the spheres position. (b) Adaptation of the initial basin surface at the movement of DEM at $t=0$ years. (c) Adaptation of the topographic surface during the evolution of an example ( $t=210$ years)
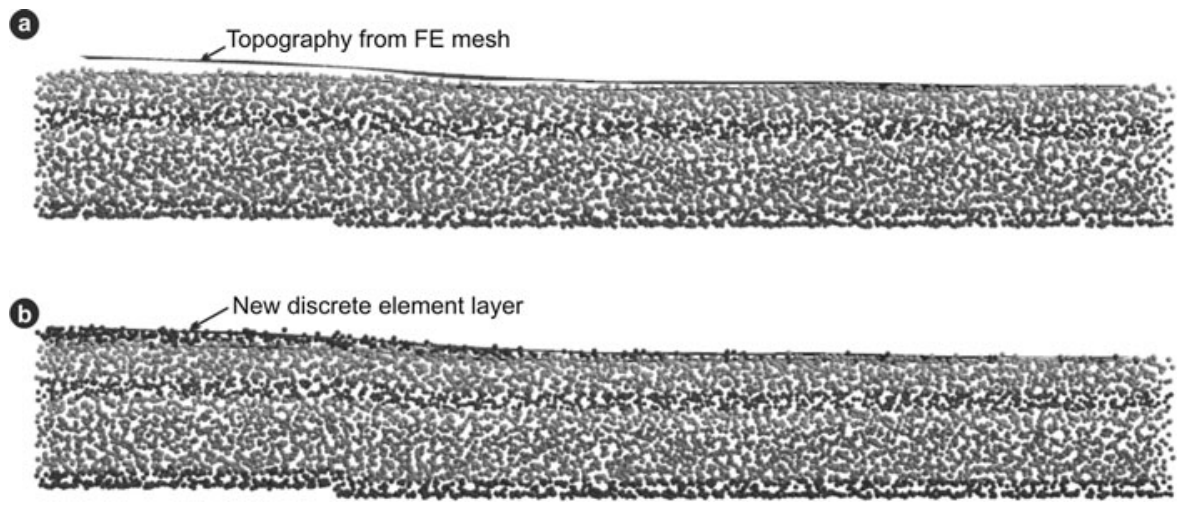

Fig. 2 Two lateral views of the same stage in the evolution of a model: (a) position of the DEM and the real topography surface which results from DEM evolution plus Simsafadim-Clastic sedimentation; (b) new discrete elements added to the DEM assemblage due to Simsafadim-Clastic sedimentation. Now the real surface is also the DEM surface

elements. This process allows the interaction of the new sediment along with the pretectonic material in the discrete element model. Moreover, the new spheres added to the DEM record the most abundant type of sediment at their location (among the four clastic sediment types that can be treated by Simsafadim-Clastic). The difference between real topography provided by Simsafadim-Clastic and the surface defined by the sphere assemblage in DEM is the amount of sediment deposited (Fig. 2a). Figure 2b shows how this sediment has been converted to discrete elements when the volume of this settled sediment is enough to undertake the transfer of from Simsafadim-Clastic 
to DEM. This interchange allows us to study the propagation of deformation in the new materials, as well as how these new sediments influence the propagation of deformation in the pre-existing cover.

\section{Examples}

In order to illustrate/check the potential of the new program, two simple examples are presented. The first one considers syntectonic sedimentation associated with an extensional fault in order to analyse the evolution and distribution of sedimentation as a result of the tectonic movement, as well as the obtained syntectonic sedimentary architecture. The second example considering syntectonic sedimentation in a thrust fault propagation environment not only deals with the structure, but also with deformation and the way in which the introduction of new sediments affect its evolution.

\subsection{Initial Configuration of the Model}

The two experiments use the same initial configuration. The DEM assemblage has a size of $250 \times 250 \times 2000 \mathrm{~m}$ and consists of 8067 spheres of four different radii: 15 , 13.75, 12.5 and 11.25 metres (Fig. 3). An initial finite element mesh of $180 \times 1800 \mathrm{~m}$ size for the Simsafadim-Clastic program is located above the assemblage surface. The mesh is divided into 32 columns and 4 rows, which results in 128 nodes or 186 triangular elements. Sealevel is fixed at a height of 0 metres. Initial topography of the basin is -100 metres for all nodes, implying an initial bathymetry of 100 metres. The program saves all information for each 60 years of simulation time. Both sample experiments are defined to be cohesionless. The coloured layers in the DEM are solely used to better visualize deformation and addition of new sediments. Results are visualized using the Datatank program and deformation is calculated using the SSPX program (Cardozo and Allmendinger 2009).

\subsection{Example 1: Syntectonic Sedimentation Associated with an Extensional Fault}

\subsubsection{Initial and Boundary Conditions}

Using the common configuration described in Fig. 3, for this extensional example, an $80^{\circ}$ dipping fault is defined in the bottom of the DE boundary (Fig. 4). The rate of displacement along the fault plane, simulating extensional fault movement,

Fig. 3 Initial discrete element (DE) assemblage used in the simulations

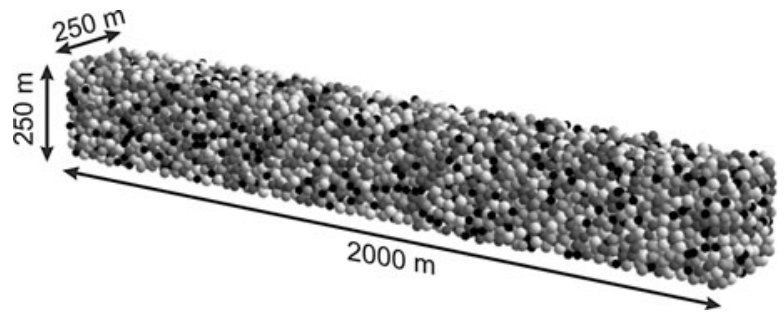




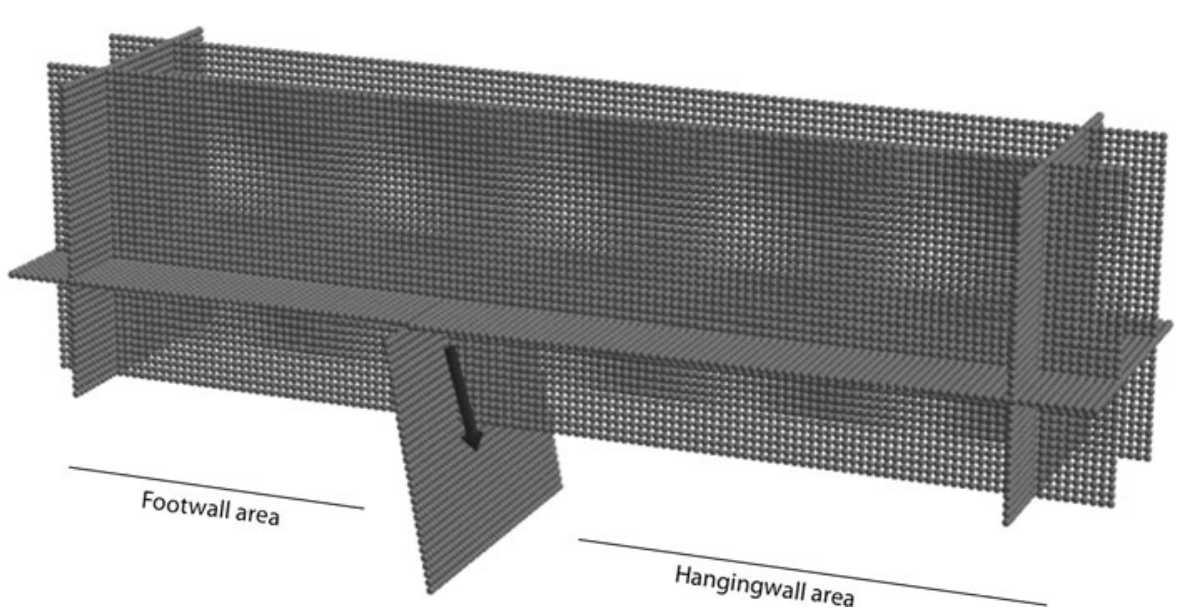

Fig. 4 Bounding box of the DE assemblage with an $80^{\circ}$ dipping fault used in the first example. The arrow shows the direction of relative movement of the hangingwall area (subsidence region) with respect to the footwall area

Table 1 Sedimentation parameters used for the first simulation considering an extensional fault

\begin{tabular}{llll}
\hline & $\begin{array}{l}\text { Clastic 1 } \\
\text { (fine) }\end{array}$ & $\begin{array}{l}\text { Clastic 2 } \\
\text { (medium) }\end{array}$ & $\begin{array}{l}\text { Clastic 3 } \\
\text { (coarse) }\end{array}$ \\
\hline $\begin{array}{l}\text { Critical velocity for } \\
\text { deposition }\left(\mathrm{m} \mathrm{s}^{-1}\right)\end{array}$ & 2.5 & 4.0 & 5.5 \\
$\begin{array}{l}\text { Settle rate } \\
\left(\mathrm{m} \mathrm{day}^{-1}\right)\end{array}$ & 0.003 & 0.004 & 0.008 \\
\hline
\end{tabular}

is $0.06 \mathrm{~m} /$ year with a total displacement of $96 \mathrm{~m}$ in dip direction during the total simulated time (1440 years). Three different clastic sediment types are simulated in the model. They are characterized through their critical velocity for deposition and rate of settling as summarized in Table 1. These values are higher for coarse materials and lower for finer ones. Inflow sediment rates are different for the different material types: they are smaller for coarser sediments than for finer ones. The inflow sediment nodes and rates are defined at a boundary node, as can be observed in Fig. 5. The fluid flow boundary conditions for the finite element mesh reproduce uniform fluid movement from the left to the right with initial velocities that allow sedimentation of the three different sediment types from the start of the experiment.

\subsubsection{Simulation Results}

Simulation results are summarized in Figs. 6, 7, and 8, where representative stages in the evolution of this example are shown. Each image in Fig. 6 shows the geometries of the DE model and the real topographic surface defined and used by the finite element mesh. Firstly, we can see that four transfers of sediment volumes from the Simsafadim-Clastic model to discrete elements take place during the simulation (remember that transfer occurs as a function of the amount of sediment deposited and 


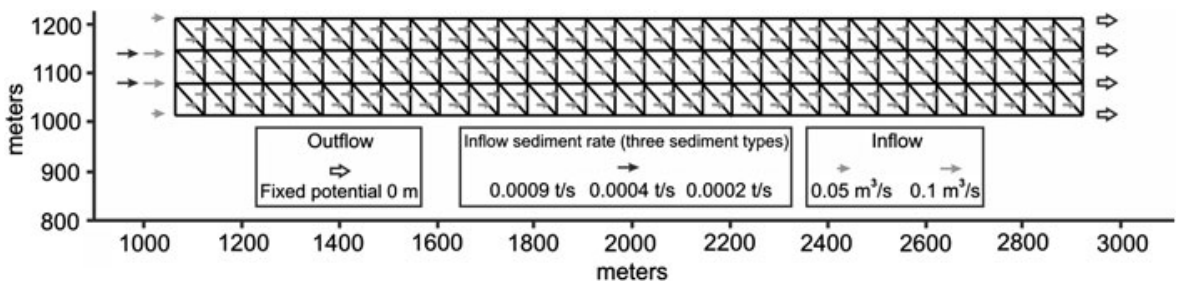

Fig. 5 Finite element mesh used by Simsafadim-Clastic in the syntectonic sedimentation associated with an extensional fault example. The boundary conditions for the inflow of water and sediment, as well as the initial fluid flow velocity vectors, are also represented

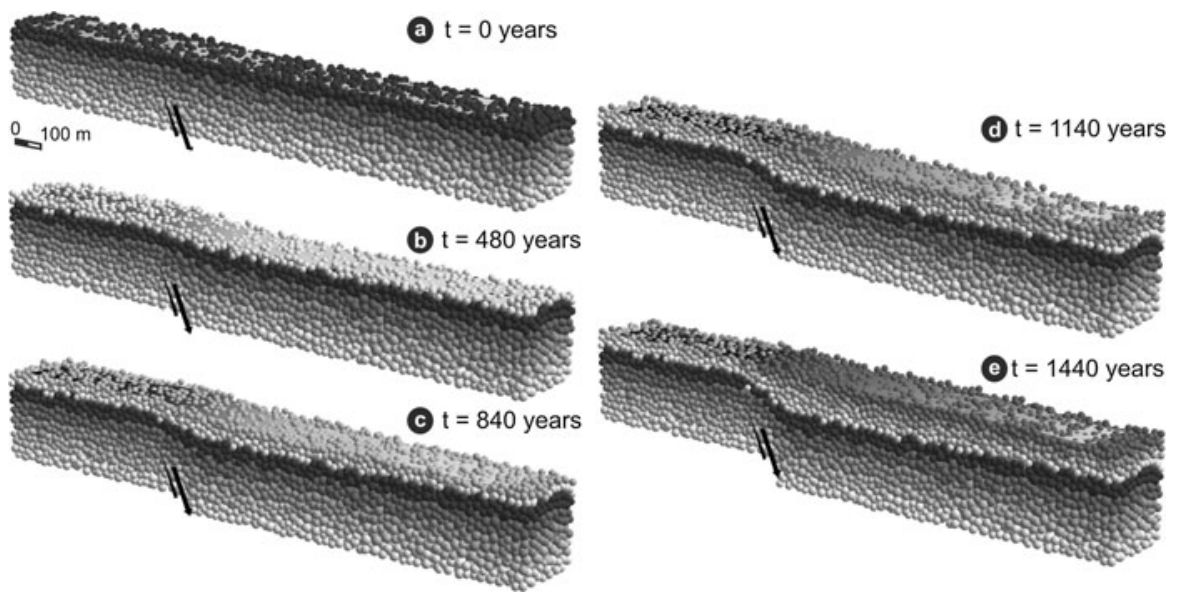

Fig. 6 Simulation results showing the evolution of syntectonic sedimentation in an extensional fault. The different images are the model at the starting configuration and just after each transfer of sediment between Simsafadim-Clastic and DEM. Four transfers of sediment take place during the simulation, which are represented by the new whiter layers. Note how sedimentation takes place mainly in the footwall area where new accommodation place is created as consequence of the fault movement. The drawn surface is the real topography at each stage, which is the result of tectonic movements plus sedimentation

DE size). These new sediments are transformed into new layers of discrete elements that become an integral part of the DEM assemblage. Focussing on the new layers (Figs. 6 and 7), we can observe that in the earliest stage (480 years) sedimentation takes place along the model, from the proximal area (located in the footwall) and decreases basinward due to sedimentation parameters and fluid flow conditions. Sedimentation in the footwall area drastically decreases during the next stage (840 years) and migrates basinward as a consequence of the water depth decrease and velocity increase due to sediment settling itself (Fig. 7). In this time step (and the next ones), sedimentation becomes more prominent in the hangingwall area where new accommodation space is created due to the subsidence associated with the normal fault movement, and where fluid flow velocity decreases because of increasing water depth. As the simulation progresses (from 1140 to 1440 years), sedimentation is progressively restricted to the hangingwall area where accommodation space continues to be created due to extensional fault movement. In the hangingwall, it is observed 

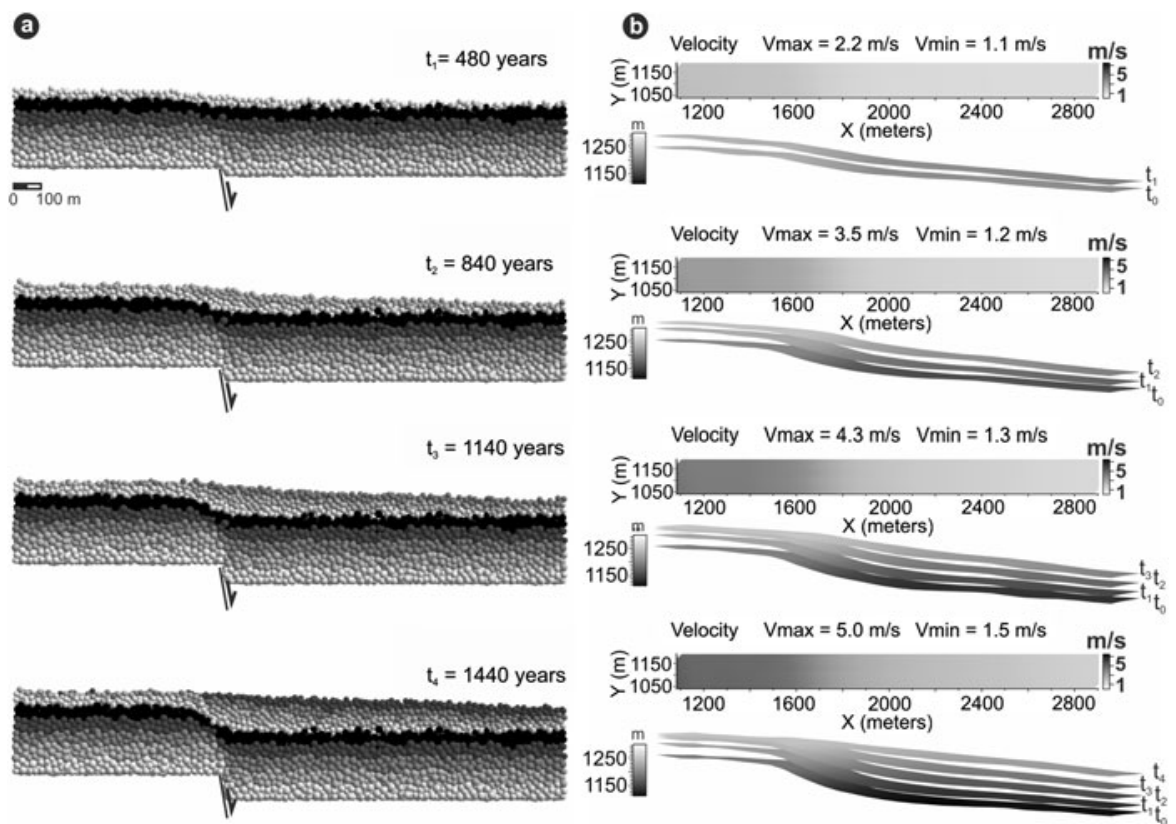

Fig. 7 Detailed representation of the evolution of the syntectonic sedimentation in an extensional fault in four different stages: (a) cross-section showing the evolution of the DEM; (b) fluid flow map of the evolution of linear velocity at each stage. The evolution of the sedimentary geometries is represented through the current topographic surface and the current position of older surfaces. Maximum and minimum linear velocity is also indicated in each time step

that during the final part of the simulation the model reaches an equilibrium phase between sedimentation and subsidence rates. As a result, the position of the topographic surface does not change considerably, and thus the fluid flow field does not change significantly. Different geometric architectures can be observed in pre- and syn-extensional materials (Figs. 6 and 7). Pre-extensional materials show a layer parallel pattern deformed near the fault area where a fault-propagation fold linked to an extensional fault system can be observed (Jin and Groshong 2006). The fold is more evident in the later time steps. Looking at the syn-extensional sediments, we can observe initial geometries resulting from the inflowing area, fluid flow system, and accommodation space (as explained before). These initial geometries are deformed near the fault zone where the same fault propagation fold geometry can be observed. Basal syn-tectonic layers are more deformed than the top one due to their existence during a longer time period. Deformation decreases upwards and away from the fault. From a Simsafadim-Clastic simulation, each discrete element can store sedimentary properties, such as percentage of each sediment type. Using these values, facies distribution can be obtained based on the most common sediment type at each discrete element (Fig. 8). Only the coarsest and finest materials are represented. This does not mean that the medium grain size material is not deposited; rather, this kind of sediment is not dominant at any location. For the whole simulation, deposition of coarser material is concentrated in the more proximal area and passes laterally to the finer 


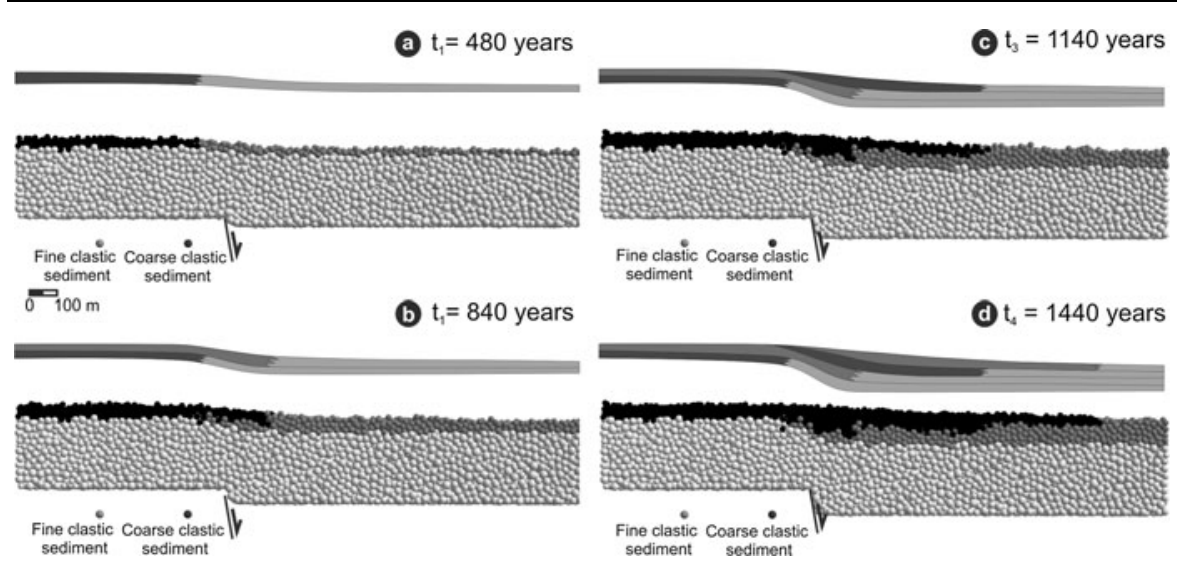

Fig. 8 Representation of spatial distribution sediment at different stages during the evolution of the first simulation: (a) 480, (b) 840, (c) 1140, and (d) 1440 years. Different colours represent the material with a higher percentage in each discrete element: light grey for the finest material and deep grey for the coarsest one. A schematic facies distribution is also represented for each stage showing the sedimentary architecture propagation

material basinward. Early stages show deposition of coarse sediments mainly in the footwall area. As a result, fluid flow increases in the footwall region at subsequent time steps due a decrease in water depth. Deposition of both materials migrates to the hangingwall area where fluid flow has considerably decreased and more accommodation space is available due to the subsidence. As simulation time moves forward, coarse sediments overlap previously deposited finer sediments, creating progradational geometries basinward.

\subsection{Example 2: Syntectonic Sedimentation and Thrust Fault Propagation}

\subsubsection{Initial and Boundary Conditions}

For the contractional sample experiment, a $45^{\circ}$ dipping fault is defined at the bottom of the DE boundary box (Fig. 9). The rate of displacement along the fault plane is defined as $0.03 \mathrm{~m} /$ year with a total displacement of 60 metres during the total simulation time (1800 years). Three different clastic sediment types are also introduced in this example. Their critical velocity for deposition and their settling rates are summarized in Table 2. Figure 10 shows the boundary conditions for fluid flow. The inflowing boundary in this example has been defined on the right side of the model, reproducing a uniform flow from right to left with initial velocities that initially allow sedimentation of the three sediment types across the model.

\subsubsection{Simulation Results}

Representative simulation results are shown in Figs. 11 and 12 at four key stages (600, 1140, 1620, and 1800 years). In Fig. 11, the detailed evolution of the model is summarized using longitudinal slices of the discrete element model. In this example, three 


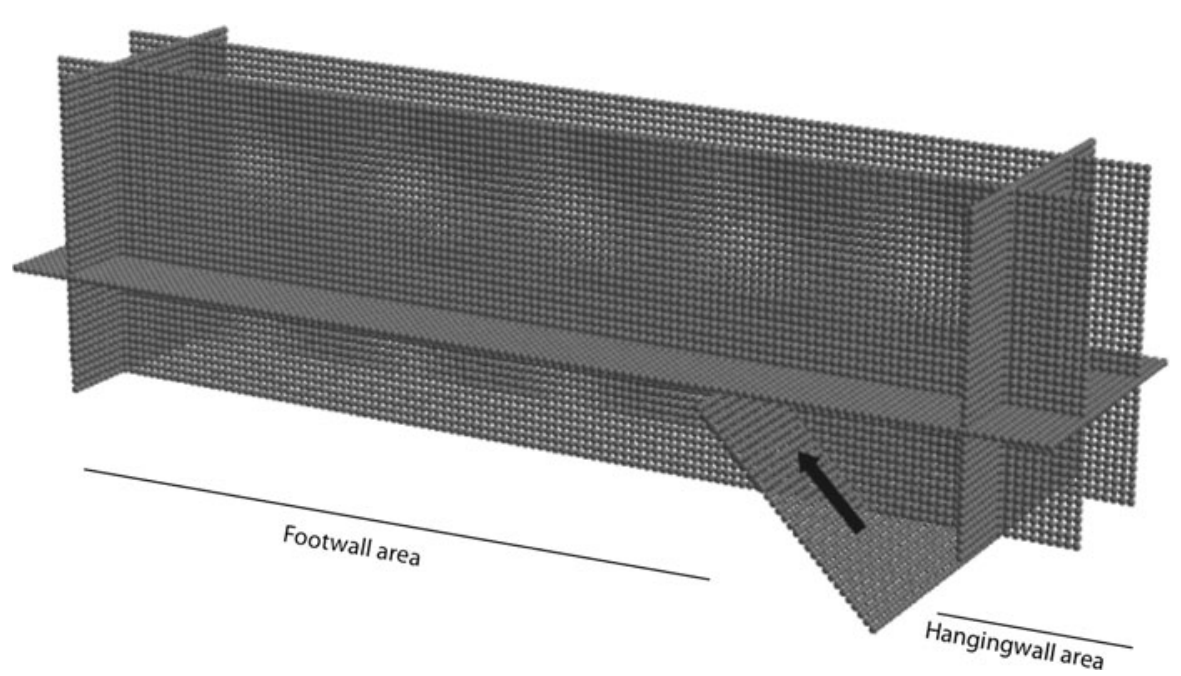

Fig. 9 Bounding box of the DE assemblage with a $45^{\circ}$ dipping fault used in the second example. The arrow shows the direction of the movement of the hangingwall area (uplifting region) with respect to the footwall area

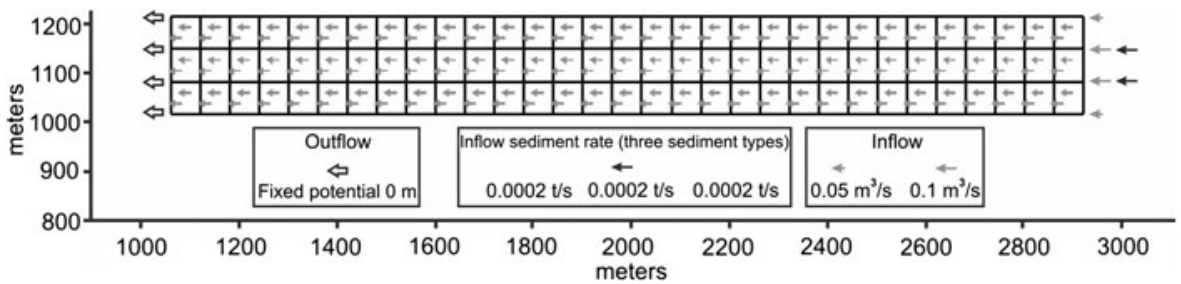

Fig. 10 Initial mesh and boundary conditions for water and sediment inflow used by Simsafadim-Clastic in the second simulation. The initial fluid flow field is also represented

Table 2 Sedimentation parameters used for the second experiment considering a thrust fault

\begin{tabular}{llll}
\hline & $\begin{array}{l}\text { Clastic 1 } \\
\text { (fine) }\end{array}$ & $\begin{array}{l}\text { Clastic 2 } \\
\text { (medium) }\end{array}$ & $\begin{array}{l}\text { Clastic 3 } \\
\text { (coarse) }\end{array}$ \\
\hline $\begin{array}{l}\text { Critical velocity for } \\
\text { deposition (m s }\end{array}$ & 3.5 & 4.5 & 5.5 \\
$\begin{array}{l}\text { Settle rate } \\
\left(\mathrm{m} \mathrm{day}^{-1}\right)\end{array}$ & 0.004 & 0.006 & 0.008 \\
\hline
\end{tabular}

transfers of sediment volumes from Simsafadim-Clastic to the DE model take place during the evolution of the model. The four stages represented are immediately after these transfers of sediment (three first stages) and the model at the final simulation time step (Fig. 11). The simulation results show how (as in the extensional example) sedimentation occurs during the first stage (600 years) in the inflowing region located 

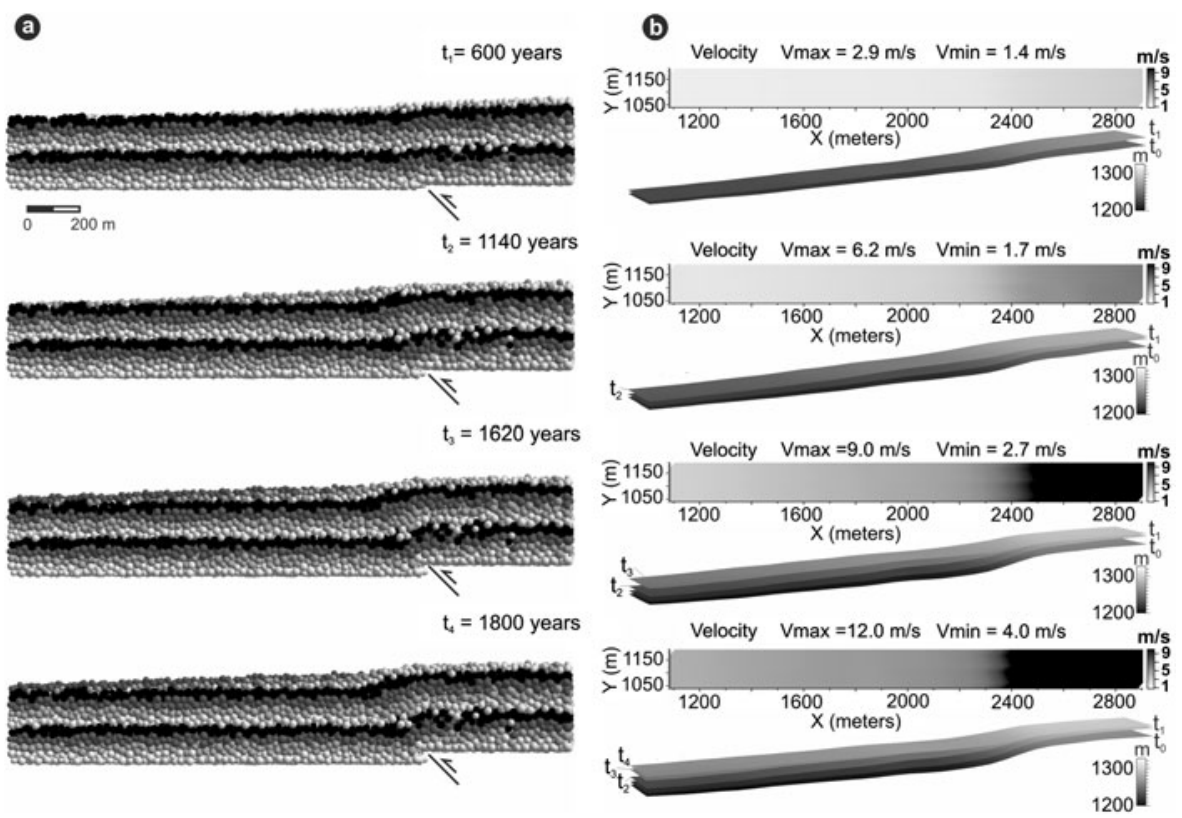

Fig. 11 Simulation results for the second simulation: (a) longitudinal cross-section of DEM; (b) syntectonic sedimentary geometries for four different stages. A fluid flow velocity map is also represented to facilitate the comprehension of the evolution of the sedimentation

on the hangingwall and how the thickness of this sedimentation decreases basinward. In the next time steps, sedimentation migrates into the basin because of the water depth decrease and fluid flow velocity increase due to sedimentation and the uplift of the hangingwall region. Consequently, the locus of sedimentation is displaced to the footwall region where accommodation space is still available. This results in a progradation of sediments into the basin and a typical offlap geometry. Using the methodology developed by Cardozo and Allmendinger (2009), we can undertake a detailed analysis of the deformation in pre- and syn-sedimentary materials (Fig. 12). Maximum Shear Strain is calculated from the displacement of all elements in the model. The shear strain is calculated between each stage. The represented time intervals in Fig. 12 have been chosen in order to show how the addition of the new sediments affects the evolution of the deformation in the model. Seven intervals have been selected: two for the time steps before the first transfer, two between each transfer, and a last one after the last transfer. The first two time intervals (up to 600 years) show how the propagation of deformation is concentrated above the fault zone where a fault-propagation fold linked to a contractive system has been developed. After the first transfer of sediment from the Simsafadim-Clastic program, we can see that the upward propagation of the deformation is firstly inhibited owing to the weight of the new material and is then reactivated after a period of time. This effect occurs whenever new sediment is transferred and added, except during the seventh time interval when this effect is not so evident because new sediment is deposited farther away from the deforming region. 


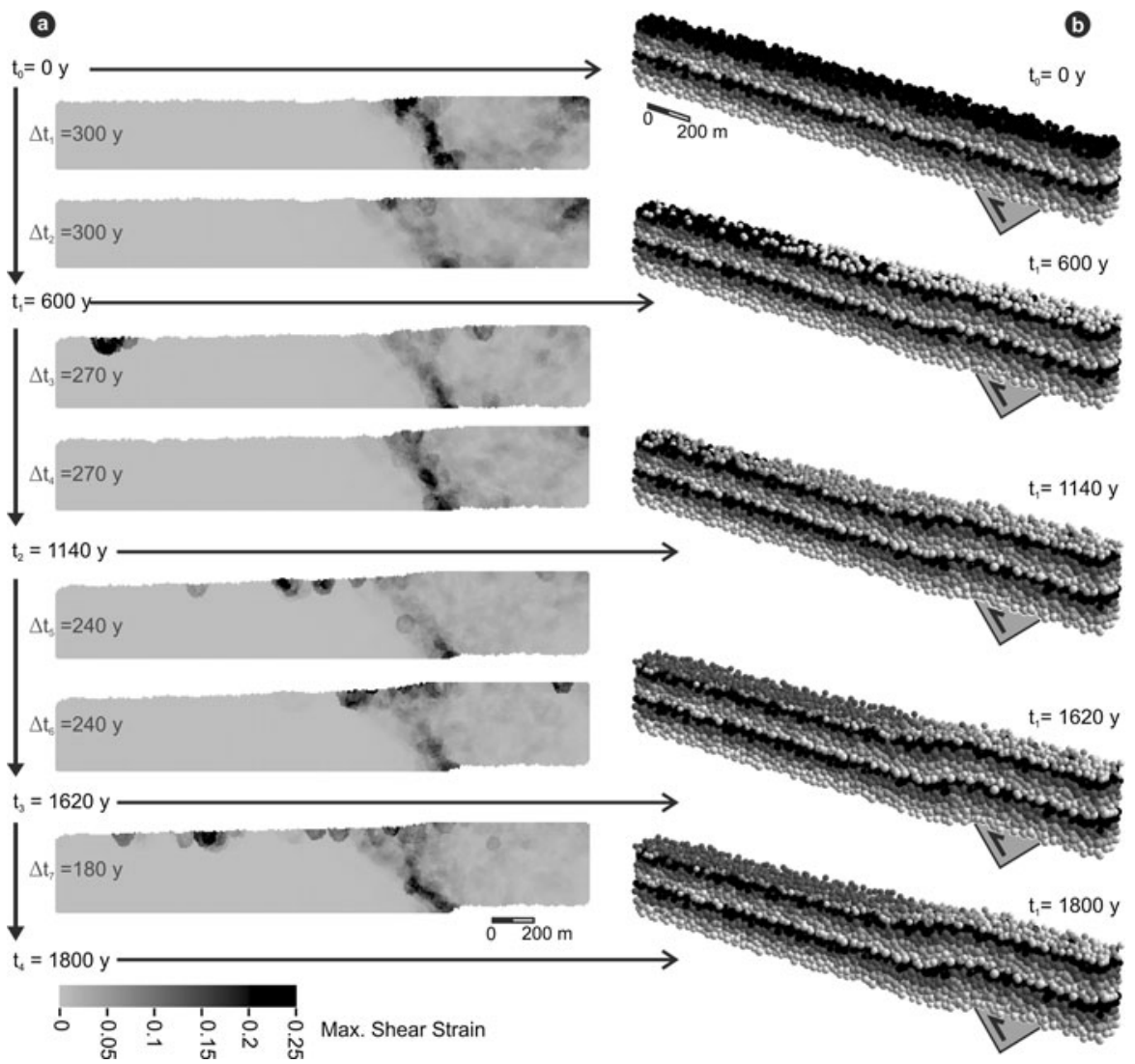

Fig. 12 Evolution of deformation considering the syntectonic sedimentation in a thrust fault propagation example using SSPX program. Maximum Shear Strain is calculated from the displacement of all elements in the model. The shear strain is calculated between each stage. The analysis is divided into seven intervals (a). DEM images, sited on the left side of the figure (b), represent the stages among which the deformation study is performed

\section{Conclusions}

This contribution has presented a new code combining two previous models, Simsafadim-Clastic and a discrete element model DEM. The new program allows us to model syntectonic sedimentation. The interest of this new code lies in the fact that it merges two completely different methods: the discrete element technique, which manages the deformation in the sedimentary cover due to tectonic movement, and the finite element method that solves the equations related to sedimentary processes in the overlying water column. We have merged the two previous algorithms by allowing them to run separately, interchanging the necessary information at each time step: DEM provides Simsafadim-Clastic with the new position of the topographic surface due to tectonic movements, while Simsafadim-Clastic supplies new sedimentary materials to DEM. New relief and new sedimentary bodies are constructed as a consequence of interaction between these two processes. In order to test the performance 
of this new merged code, two example simulations that take into account sedimentation associated with the growth of a normal fault and a reverse fault are presented. Each example has been defined with a different set of initial and boundary conditions for fluid flow, transport, and sedimentation, as well as different tectonic boundary conditions and displacement rates. Results obtained by both experiments show realistic syntectonic stratigraphic architectures. The evolution of the basin topography in the two examples is the result of both tectonic movements and sedimentation. Fluid flow and, consequently, transport and sedimentation change according to this evolving topography. The depositional sedimentary bodies are similar to reported natural examples in each case. The transfer of sediments from Simsafim-Clastic to DEM allows us to have more realistic deformed sedimentary bodies as a result of the tectonic movements occurring in a basin. It is also noted that the propagation of the deformation is affected by the addition of syntectonic sediments into the model. The results of both experiments support the viability of the approach of combining the two models (i.e. Simsafadim-Clastic and DEM) and also the realism of model results. We can conclude that this new tool allows us to perform a more realistic and detailed study of the way sedimentation and tectonics interact in nature.

Acknowledgements This research was carried out by the GEOMODELS Research Institute and the CRG Geodynamics and Basin Analysis (2001SGR_000074) of the University of Barcelona. This work was supported by StatoilHydro (project 4D Modelling Based on Field Descriptions, project nr. 5348768) and the project MODES-4D (CGL2007-66431-CO"/BTE). The original manuscript has been improved thanks to the valuable comments by Dr. Harff, an anonymous reviewer, and the guests' editor, Jef Caers.

\section{References}

Allen MP, Tidsley DJ (1987) Computer simulations of liquids. Oxford Science Publications, Oxford

Allmendinger RW (1998) Inverse and forward numerical modelling of trishear fault propagation folds. Tectonics 17:640-656

Bitzer K, Salas R (2002) SIMSAFADIM: three dimensional simulation of stratigraphic architecture and facies distribution modelling of carbonate sediments. Comput Geosci 28:1177-1192

Cardozo N, Allmendinger RW (2009) SSPX: a program to compute strain from displacement/velocity data. Comput Geosci 35(6):1343-1357

Cardozo N, Bawa-Bhalla K, Zehnder A, Allmendinger RW (2003) Mechanical models of fault propagation folds and comparison to the trishear kinematic model. J Struct Geol 25:1-18

Finch E, Hardy S, Gawthorpe R (2003) Discrete element modelling of contractional faults-propagation folding above rigid basement rocks. J Struct Geol 25:515-528

Finch E, Hardy S, Gawthorpe R (2004) Discrete element modelling of extensional faults-propagation folding above rigid basement rocks. Basin Res 16:489-506

Gawthorpe R, Hardy S (2002) Extensional fault-propagation folding and base-level changes as controls on growth strata geometries. Sediment Geol 146:47-56

Grajeon D, Joseph P (1999) Concepts and applications of a 3-D multiply lithology, diffusive model in stratigraphic modelling. In: Harbaugh J, Watney W, Rankey E, Slingerland R, Goldstein R, Franseen E (eds) Numerical experiments in stratigraphy: recent advances in stratigraphic and sedimentologic computer simulations. SEPM special publications, vol 62. Kansas Geological Survey, Lawrence, pp 197-210

Gratacós O (2004) Simsafadim-Clastic: modelización 3D de transporte y sedimentación Clástica Subacuática. Tesis doctoral, Universitat de Barcelona

Gratacós O, Bitzer K, Cabrera L, Roca E (2009a) SIMSAFADIM-CLASTIC: a new approach to mathematical 3D forward simulation modelling for clastic and carbonate sedimentation. Geol Acta 7:311-322

Gratacós O, Bitzer K, Casamor JL, Cabrera L, Calafat A, Canals M, Roca E (2009b) Simulating transport and deposition of clastic sediments in an elongate basin using the SIMSAFADIM-CLASTIC program: The Camarasa artificial lake case study (NE Spain). Sediment Geol 222(1-2):16-26 
Hardy S (2008) Structural evolution of calderas: insights from two-dimensional discrete element simulations. Geol Soc Am 36(12):927-930

Hardy S, Finch E (2005) Discrete-element modelling of detachment folding. Basin Res 17:507-520

Hardy S, Finch E (2006) Discrete element modelling of the influence of cover strength on basementinvolved fault-propagation folding. Tectonophysics 415:225-238

Hardy S, Finch E (2007) Mechanical stratigraphy and the transition from trishear to kink-band faultpropagation fold forms above blind basement thrust faults: a discrete-element study. Mar Pet Geol 24:75-90

Hardy S, Gawthorpe R (1998) Effects of variations in fault slip rate on sequence stratigraphy in fan deltas. Mar Pet Geol 11(5):911-914

Hardy S, McClay K (1999) Kinematic modelling of extensional fault-propagation folding. J Struct Geol 21:695-702

Hardy S, McClay K, Muñoz JA (2009) Deformation and fault activity in space and time in high-resolution numerical models of doubly vergent thrust wedges. Mar Pet Geol 26(2):232-248

Jin G, Groshong RH (2006) Trishear kinematic modeling of extensional fault-propagation folding. J Struct Geol 28:170-183

Johnson KM, Johnson AM (2002) Mechanical models of trishear-like folds. J Struct Geol 24:277-287

Kinzelbach W (1986) Groundwater modelling: an introduction with sample programs in BASIC. Elsevier, Amsterdam

Li M, Amos C (2001) SEDTRANS96: the upgraded and better calibrated sediment-transport model for continental shelves. Comput Geosci 27:619-645

Maniatis G, Kurfeß D, Hampel A, Heidbach O (2009) Slip acceleration on normal faults due to erosion and sedimentation-Results from a new three-dimensional numerical model coupling tectonics and landscape evolution. Earth Planet Sci Lett 284:570-582

Mora P, Place D (1993) A lattice solid model for the non-linear dynamics of earthquakes. Int J Modern Phys C 4(6): 1059-1074

Mora P, Place D (1994) Simulation of the frictional stick-slip instability. Pure Appl Geophys 143(1-3): 61-87

Simpson GDH (2006) Modelling interactions between fold-thrust belt deformations, foreland flexure and surface mass transport. Basin Res 18:125-144

Simpson GDH (2009) Mechanical modelling of folding versus faulting in brittle-ductile wedges. J Struct Geol 31:369-381

Strayer LM, Suppe J (2002) Out-of plane motion of a thrust sheet during along — strike propagation of a thrust ramp: a distinct element approach. J Struct Geol 24:637-650

Tetzlaff DM, Harbaugh JW (1989) Simulating Clastic Sedimentation. Computer Methods in Geology. Van Nostrand and Reinhold, New York 